\title{
㐘
}

\section{ENTRE PAISAGENS E PANORAMAS: FOTOGRAFIA E METÁFORAS VISUAIS}

\author{
- CAIO AUGUSTO AMORIM MACIEL ${ }^{1}$ \\ Doutor em Geografia, Pós-Graduação em Geografia - UFPE. E-mail: caio.maciel@ufpe.br
}

\section{- PRISCILA BATISTA VASCONCELOS ${ }^{2}$}

Doutora em Geografia, Departamento de Ciências Geográficas - UFPE. E-mail: priscila.vasconcelos@ufpe.br

Recebido em: $13 / 11 / 2020$

Aprovado em: 15/12/2020

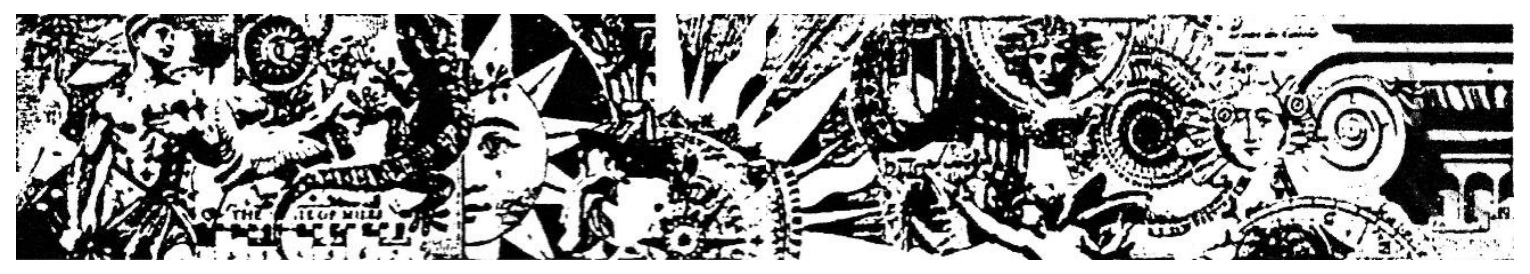

Resumo: A fotografia, apesar do largo emprego na geografia, raramente ultrapassa o estatuto de ilustração ou arquivo documental. Neste artigo, ao contrário do traço ilustrativo dominante, tratamo-la em seu caráter híbrido (arte, conhecimento e informação), propondo uma investigação cultural de espaços tornados "invisíveis", entre outras questões, por seu caráter recôndito e impeditivo a grandes vistas. Assim, a partir de estudos sobre becos do Centro Histórico do Recife propomos uma reflexão sobre o uso de fotografias como recurso metodológico na Geografia Cultural. $O$ trabalho pretende, mais do que apresentar um estudo de caso, refletir sobre o tema das paisagens não panorâmicas, almejando estabelecer parâmetros mais gerais sobre a relação entre "contemplação produzida", a mobilização de panoramas para incitar análises geográficas e o processo de registro/produção de fotografias/panoramas por geógrafos-fotógrafos como instrumental de pesquisa. Optamos pelo recurso à produção autoral de uma fachada-prancha como estratégia heurística para apresentar 0 ambiente fissural das vielas, não imediatamente visível, à guisa de um quadro geográfico. A técnica recompõe a experiência sensível dos autores naquele espaço, reforçando a pertinência da fotografia na investigação geográfica, não apenas para desconstruir estereótipos, mas, sobretudo, para expor o poder de agência das próprias imagens, as quais interferem na estruturação material dos lugares e no acionamento de metáforas visuais que organizam a sociedade

Palavras-Chave: Paisagem; Panorama; Fotografia; Metáfora visual. 


\section{BETWEEN LANDSCAPES AND PANORAMAS: PHOTOGRAPHY AND VISUAL METAPHORS}

ABSTRACT: PHOTOGRAPHY, DESPITE ITS WIDE EMPLOYMENT IN GEOGRAPHY, RARELY EXCEEDS THE STATUS OF ILLUSTRATION OR DOCUMENTARY ARCHIVE. IN THIS ARTICLE, CONTRARY TO THE DOMINANT ILLUSTRATIVE TRACE, WE TREAT IT IN ITS HYBRID CHARACTER (ART, KNOWLEDGE AND INFORMATION), PROPOSING A CULTURAL INVESTIGATION OF SPACES MADE "INVISIBLE", AMONG OTHER ISSUES, BY THEIR HIDDEN CHARACTER AND IMPEDIMENT TO GREAT VIEWS. THUS, FROM STUDIES ON LANES IN THE HISTORIC CENTRE OF RECIFE WE PROPOSE A REFLECTION ON THE USE OF PHOTOGRAPHS AS A METHODOLOGICAL RESOURCE IN CULTURAL GEOGRAPHY. THE WORK INTENDS, RATHER THAN PRESENTING A CASE STUDY, TO REFLECT ON THE THEME OF NONPANORAMIC LANDSCAPES, AIMING TO ESTABLISH MORE GENERAL PARAMETERS ON THE RELATIONSHIP BETWEEN "INDUCED CONTEMPLATION", THE MOBILIZATION OF PANORAMAS TO INCITE GEOGRAPHIC ANALYSIS, AND THE PROCESS OF REGISTERING/PRODUCING PHOTOGRAPHS/PANORAMAS BY GEOGRAPHERS/PHOTOGRAPHERS AS A RESEARCH INSTRUMENT. WE CHOSE TO USE THE AUTHORIAL PRODUCTION OF A SHEET FAÇADE AS A HEURISTIC STRATEGY TO PRESENT THE FISSURAL ENVIRONMENT OF THE ALLEYS, NOT IMMEDIATELY VISIBLE, BY MEANS OF A GEOGRAPHICAL PICTURE. THE TECHNIQUE RECOMPOSES THE SENSITIVE EXPERIENCE OF THE AUTHORS IN THAT SPACE, REINFORCING THE RELEVANCE OF PHOTOGRAPHY IN GEOGRAPHICAL RESEARCH, NOT ONLY TO DECONSTRUCT STEREOTYPES, BUT ABOVE ALL TO EXPOSE THE AGENCY OF THE IMAGES THEMSELVES, WHICH INTERFERE IN THE MATERIAL STRUCTURING OF PLACES AND THE TRIGGERING OF VISUAL METAPHORS THAT ORGANIZE SOCIETY

KEYWORDS: LANDSCAPE, PANORAMA, PHOTOGRAPHY, VISUAL METAPHOR.

\section{ENTRE PAISAJES Y PANORAMAS: FOTOGRAFÍA Y METÁFORAS VISUALES}

RESUMEN: LA FOTOGRAFÍA, A PESAR DE SU AMPLIO USO EN LA GEOGRAFÍA, CASI NUNCA SUPERA EL ESTATUS DE ILUSTRACIÓN O ARCHIVO DOCUMENTAL. EN ESTE ARTÍCULO, CONTRARIAMENTE AL RASTRO ILUSTRATIVO DOMINANTE, LA TRATAMOS EN SU CARÁCTER HÍBRIDO (ARTE, CONOCIMIENTO E INFORMACIÓN), PROPONIENDO UNA INVESTIGACIÓN CULTURAL DE LOS ESPACIOS QUE SE HAN HECHO "INVISIBLES", ENTRE OTRAS CUESTIONES, DEBIDO A SU CARÁCTER OCULTO Y AL IMPEDIMENTO DE LAS GRANDES VISTAS. ASÍ, A PARTIR DE LOS ESTUDIOS DE LOS CALLEJONES DEL CENTRO HISTÓRICO DE RECIFE, PROPONEMOS UNA REFLEXIÓN SOBRE EL USO DE LAS FOTOGRAFÍAS COMO RECURSO METODOLÓGICO EN LA GEOGRAFÍA CULTURAL. EL ARTÍCULO PRETENDE, MÁS QUE PRESENTAR UN ESTUDIO DE CASO, REFLEXIONAR SOBRE EL TEMA DE LOS PAISAJES NO PANORÁMICOS, CON EL FIN DE ESTABLECER PARÁMETROS MÁS GENERALES SOBRE LA RELACIÓN ENTRE LA "CONTEMPLACIÓN PRODUCIDA", LA MOVILIZACIÓN DE LOS PANORAMAS PARA INCITAR AL ANÁLISIS GEOGRÁFICO Y EL PROCESO DE REGISTRO/PRODUCCIÓN DE FOTOGRAFÍAS/PANORAMAS POR PARTE DE GEÓGRAFOS/FOTÓGRAFOS COMO INSTRUMENTO DE INVESTIGACIÓN. OPTAMOS POR EL USO DE LA PRODUCCIÓN AUTORAL DE UNA FACHADA DE LÁMINAS COMO ESTRATEGIA HEURISTICA PARA PRESENTAR EL ENTORNO FISURAL DE LOS CALLEJONES, NO VISIBLE INMEDIATAMENTE, MEDIANTE UNA IMAGEN GEOGRÁFICA. LA TÉCNICA RECOMPONE LA EXPERIENCIA SENSIBLE DE LOS AUTORES EN ESE ESPACIO, REFORZANDO LA RELEVANCIA DE LA FOTOGRAFÍA EN LA INVESTIGACIÓN 
GEOGRÁFICA, NO SÓLO PARA DECONSTRUIR LOS ESTEREOTIPOS, SINO SOBRE TODO PARA EXPONER EL PODER DE AGENCIA DE LAS PROPIAS IMÁGENES, QUE INTERFIEREN EN LA ESTRUCTURACIÓN MATERIAL DE LOS LUGARES Y LA ACTIVACIÓN DE LAS METÁFORAS VISUALES QUE ORGANIZAN LA SOCIEDADE.

\title{
PALABRAS CLAVE: PAISAJE, PANORAMA, FOTOGRAFÍA, METÁFORA VISUAL
}

\section{Paisagem, fotografia e artialização: panoramas}

\begin{abstract}
A fotografia pode comunicar sobre a cultura, a vida das pessoas, experiências e crenças, não no nível da descrição superficial, mas como uma metáfora visual, que liga os espaços entre o visível e o invisível, que não comunica por meio de um paradigma realista, mas por meio de uma expressividade lírica (Elisabeth Edwards, in: Sylvia Caiuby Novaes, 2015, p.10).
\end{abstract}

No presente artigo, ao contrário do traço ilustrativo dominante, invocamos a partir de Caiuby Novaes (2015, p.9) o caráter híbrido da fotografia - arte, conhecimento e informação - para uma investigação cultural de espaços tornados "invisíveis" por força de vicissitudes da sociedade de que fazem parte: os becos do Centro Histórico do Recife. Todavia, mais que um estudo de caso como tratado em momentos anteriores (VASCONCELOS e MACIEL, 2016; VASCONCELOS, MACIEL e LACERDA, 2018), propomos agora uma reflexão sobre o tema das paisagens panorâmicas e não panorâmicas, almejando estabelecer parâmetros mais gerais sobre a relação entre "contemplação produzida", a mobilização de panoramas para incitar análises geográficas e o processo de registro/produção de fotografias/panoramas por geógrafos-fotógrafos como instrumental de pesquisa.

A produção de instrumentos básicos de descrição daqueles espaços objetivou compartilhar escolhas e julgamentos que evidenciassem seu potencial proveito para uma forma de pensar geográfica, no sentido de que "as imagens possuem a capacidade de mostrar aos olhos do observador aquilo que ele habitualmente olha, mas não vê” (GOMES, 2017, p.27). Como dissemos em outra oportunidade, analisar os becos nos colocou na linha do chão e seus desafios: primeiro, observar o lugar das ruelas na dinâmica de pequena escala no âmbito de um perímetro tombado; em seguida, considerá-los no contexto territorial e paisagístico maior em que o bairro se insere (Centro Histórico do Recife) e, por fim, balizar o exercício do olhar a partir da hipótese de que o "regime escópico" que orienta as visualidades e imagens possíveis do espaço patrimonializado do bairro de São José tende a invisibilizar aquelas vias. 
Ao fotografar becos, questionamos o quanto não são expressivos como os grandes e formosos monumentos - pátios, igrejas barrocas, casarios do século XIX etc. - muito embora façam parte de uma mesma paisagem cultural. Almejamos tornar visível o pouco visto, interpelando o senso comum acerca dos "maus lugares". Nada extrovertidos imageticamente, avessos a panoramas, esses espaços não deixam de ser simbólicos quanto a nossos desejos, memórias, modos e até medos (VASCONCELOS, MACIEL e LACERDA, 2018, p.98)

Partindo dessas experiências, aceitamos os desafios de pensar por imagens e com imagens (GOMES e RIBEIRO, 2013), optando agora pelo recurso à produção autoral de uma fachada-prancha fotográfica para possibilitar uma visão de conjunto do ambiente fissural das vielas, reapresentando o não imediatamente visível à guisa de uma cartografia. Esboçamos uma fachada imaginária para reparar se, assim, poderíamos descobrir algo novo sobre aqueles logradouros estreitos em especial - e sobre as paisagens não panorâmicas, em geral.

A técnica suscitou uma recomposição da experiência sensível dos autores naquele contex to espacial, mediando o textual, o perceptual e o iconográfico, num processo alternativo de produção e expressão do conhecimento geográfico. Isto é, a descrição/construção visual de um espaço recôndito mediante justaposição de fotografias seccionais foi testada enquanto dispositivo de sondagem e mapeamento fotográfico em íntima relação com as propriedades morfológicas e imaginárias daquele ambiente urbano.

Na gênese deste dispositivo reside um salto cognitivo que se reporta a um discurso sobre paisagem que nem é panorâmica, nem compartilha socialmente valores e concepções estéticas favoráveis: como se sabe, são vias estreitas, apinhadas de pessoas e de objetos os mais variados, tidas no passado como lugar de "gentinha" e áreas de serviço (VASCONCELOS e MACIEL, 2016). De modo que, para tornar os becos paisagem, precisamos proceder a um processo de artialização (ROGER, 1997): transformar aquele espaço visível em algo apreciável, interessante, revelador, belo de alguma sorte.

Não custa lembrar, apoiando-nos em Teresa Alves no seu comentário acerca da obra de Alain Roger, que a noção tradicional de paisagem era associada a uma viva impressão de deleite, “mas até serem 'transformados' em paisagem os espaços das montanhas, das florestas, dos desertos ou do mar eram espaços penosos e repulsivos” (ALVES, 2001, p.69). Hoje, qualquer território do cotidiano se tornou paisagem, compondo cenários em contínua transformação, o que em muito se deve às facilidades atuais de produzirmos fotos, de tal modo que "temos a sensação de que não apenas tudo existe para terminar numa foto, mas também que tudo o que existe já foi fotografado (VELAZCO e CRUZ in SALAZAR, 2018, p.15). Como quer que seja, a ação "artializadora" consiste aqui em tornar os ambientes restritos e habituais 
das ruelas em imagens dignas de admiração - e numa abertura do olhar que remete ao panorama.

O exercício metodológico de fotografar os becos do Recife nos conduziu à sua peculiar relação com imagens não-totalizantes, partindo do eminentemente não-panorâmico à produção de uma realidade virtual: a própria fachada-prancha, gerando um quadro que é “infotografável” a partir de uma só tomada (panorama fantasmático). Isto transformou o modo como refletimos sobre a natureza mesma desses espaços fissurais, ao mesmo tempo em que nos instigou a considerar vontades de paisagem ali presentes: desejos e necessidades de contemplação “intrínseca” (para dentro), duplamente interpeladora: beco é paisagem, mas desfruta-se diversamente de uma vista abrangente, em perspectiva ou de conjunto de dado espaço físico. O não-panorâmico pode ser ali um labirinto retilíneo ou quadricular de imagens que a ação cultural dos sujeitos põe em composição, a partir de vivências do transitar, do estar e do ver. Criam-se "paisagens-mosaicas”, tal que panoramas.

O tema coaduna-se, ainda, com os debates acerca de cidadania paisagística (RIBEIRO, 2013; BARBOSA, 2018), uma vez que esta deve incorporar não só ações e discursos que mobilizam a paisagem de determinados grupos desfavorecidos ou lugares metonímicos, como também pode pôr a prova os próprios cânones que instauram certos espaços como fachadas representativas da urbe, enquanto outros são escondidos porquanto inadaptados àquilo que se pretende fazer ver. De tal modo que,

[...] no debate paisagístico contemporâneo podemos observar a formulação de discursos e ações que articulam demandas de reconhecimento social à valoração de horizontes paisagísticos. Ações que atribuem um papel central à paisagem nas lutas por direitos, a partir da expressão daquilo que gostaríamos de nomear como vontades de paisagem, como um desejo crescente, expresso por grupos diversos, de se sentirem representados nos horizontes paisagísticos, de ter seu estar no mundo, suas marcas territoriais e expressões simbólicas reconhecidas e valoradas (BARBOSA, 2018, p.49-50, grifos nossos).

Por exemplo, na ação artística colaborativa multimídia "Guia Comum do Centro do Recife. Arqueologia do Presente" ${ }^{1}$, que mapeia lugares e situações de resistência no centro da cidade desde 2015 (apoiando-se em publicações, plataformas digitais e aplicativos para telefonia móvel), o Beco do Veado, uma das mais icônicas travessas do bairro de São José, no Centro Histórico do Recife, é apresentado em vídeo com clara demanda de reconhecimento

\footnotetext{
${ }^{1}$ Ver página principal do projeto artístico "Guia Comum do Centro do Recife” no Facebook, disponível em: https://www.facebook.com/pg/guiacomumdocentrodorecife/about/?ref=page_internal, acessado em 11/11/2020. O mesmo foi transformado em um aplicativo de celular, o "Guia Comum do Recife".
} 
socioespacial: “...é um exemplo do convívio pessoal e afetivo que ainda existe no comércio popular do Centro do Recife"; trata-se de um espaço famoso pela concentração de amoladores de alicate, "com histórias divertidas e um clima bem familiar", consistindo num lugar que "mora no coração de todos que amam a cidade"'.

Para Bruna Férrer Morais (MORAIS, CESAR et al., 2015), uma das integrantes da ação, o Guia Comum aponta para uma outra forma de contemplação, uso e percepção da cidade, visto que consiste numa tentativa de mapear lugares de invisibilidade ou abandono público, sendo comum “justamente porque ele aborda lugares e situações cotidianas bastante banais, no melhor sentido da palavra"3. A estratégia de uma arqueologia do banal contemporâneo condiz com a noção de Susan Sontag, para quem as fotos não seriam tanto um substituto da memória, mas sim instrumentos de memória (SONTAG, 2004, p.181).

O registro das paisagens dos becos recifenses, em consonância com os conteúdos e opiniões expressos no Guia Comum, é amplamente cidadão no sentido apontado por Barbosa (2018), quer dizer, de demanda por construir uma visibilidade social a partir de um interesse público da coletividade por outras memórias - trata-se, por conseguinte, de uma visão insurgente que em nada lembra a antiga conotação de maus lugares das vielas. Sustentamos que vários logradouros do centro vivenciam reabilitações similares, pois, como adverte Claval, nunca a experiência geográfica, o significado dos lugares e o papel das paisagens chamou tanto a atenção para a instauração de novas ordens simbólicas por grupos humanos quanto na atualidade (CLAVAL, 2010, p.130).

De sorte que o presente estudo, reconhecendo a expressão simbólica dos becos como elemento-chave do seu direito à paisagem, de ser parte da paisagem cultural do Centro Histórico, reforça a pertinência da fotografia autoral na pesquisa geográfica, não apenas para revelar espaços “invisíveis" e desconstruir estereótipos, mas, sobretudo, para expor o poder de agência das próprias imagens, as quais interferem na estruturação material ou imaginária dos lugares e no acionamento de metáforas visuais que organizam a sociedade. Fotografias reapresentam espaços em outros níveis de visibilidade, tornando-os paisagens - daí conquistam territórios, fazendo o que se considera feio, banal ou imperceptível tornar-se admirável, desejado.

\footnotetext{
${ }^{2}$ Vídeo "Guia Comum do Centro do Recife - Beco do Veado" (LIS - Laboratório de Imagem e Som da UFPE, DECOM - Departamento de Comunicação Social da UFPE e TVU - TV Universitária de Pernambuco, 2016), disponível em: https://www.youtube.com/watch?v=eZTfDevnlXs, acessado em 10/09/2020.

${ }^{3}$ Depoimento em vídeo para o Guia Comum do Centro do Recife - Apresentação (LIS - UFPE, 2016), disponível em https://www.youtube.com/watch?v=3g6-GDNeG-s, acessado 14/09/2020.
} 
Pretendemos, por conseguinte, demonstrar que paisagens não panorâmicas são perfeitamente contempláveis mediante um exercício de produção artística/científica de quadros geográficos, tal como mapas trazem aos nossos olhos extensões que não estamos aptos, organicamente, a discernir - ou como mosaicos nos permitem imaginar uma grande figura a partir da reunião de pequenas peças. Sem embargo, admirar o não panorâmico requer intimidade, espera, vivência espacial e desenvolvimento do senso de organização e escala, para decifrar múltiplas combinações de objetos, cores, materiais e formas. Exige, acima de tudo, uma razão metafórica para montar paisagens onde a vista não alcança. Passemos, então, à tentativa de fotografar o beco.

\title{
Desafios e estratégias para uma “contemplação produzida” de paisagens não- panorâmicas
}

\begin{abstract}
A fotografia não apenas reproduz o real, recicla-o - um procedimento fundamental numa sociedade moderna. Na forma de imagens fotográficas, coisas e fatos recebem novos usos, destinados a novos significados, que ultrapassam as distinções entre o belo e o feio, o verdadeiro e o falso, o útil e o inútil, bom gosto e mau gosto. A fotografia é um dos principais meios de produzir esse atributo, conferido às coisas e situações, que apaga aquelas distinções: "o interessante". (SONTAG, 2004, p.191).
\end{abstract}

O Beco do Marroquim, abertura que liga a Rua Cais de Santa Rita à Rua da Penha, é um desses espaços ordinários do Centro Histórico do Recife, porém revestido de uma especial dimensão prática e simbólica para os frequentadores do comércio popular de São José. De fato, a viela é amiúde referida como uma das mais organizadas do bairro, consistindo num "bom lugar para desfrutar de um pouco de sombra, já que o teto é coberto, e de menos balbúrdia. Lá existe de tudo, desde comida a bolsas e artesanatos. Ainda assim, mantém-se limpa e organizada graças aos próprios comerciantes, que se revezam na tarefa” (JORNAL DO COMMERCIO, 2012). O recorte foi escolhido, pois, em função dessas características de grande fluxo e representatividade do burburinho, consistindo por isso mesmo num sítio mais resistente ao esquecimento que acomete outras partes da região central da cidade.

O estratagema investigativo do experimento de produção de uma visão "mosaicopanorâmica" do beco girou em torno da criação de imagens autorais sucessivas e justapostas, parte de uma fachada fantasmática do Marroquim, em seu segmento de aproximadamente 50 metros de comprimento, situado entre duas ruas (do Rangel e da Penha). A colagem resultante consistiu num mosaico de $8 \mathrm{~m}$ de comprimento e $42 \mathrm{~cm}$ de altura, consistido numa escala 
aproximada de 1/6,5. Com isso, buscamos a emergência de processos cognitivos de composição e leitura do espaço, mais do que criar puramente novas representações.

Produzir e analisar o mosaico nos remeteu aos modos de fabricação de quadros geográficos não estritamente cartográficos. Inicialmente a tira de imagens resultante (figura 1) nos evocou, de maneira bem pragmática, as relações dos segmentos do beco com os empreendimentos que lhes são contíguos, assim como nos fez realizar o quanto as entradas são ambientes bastante valorizados pelo mais fácil acesso às ruas - as bocas do logradouro são mais expostas e confundem-se com as entradas de magazines. Do lado leste (acesso pela rua da Praia), o comércio de tecidos artesanais, roupas e redes está em consonância com uma das mais antigas lojas de têxteis de Pernambuco, o Fortunato Russo ${ }^{5}$. Já do lado oeste, a partir da rua da Penha, fenômeno similar ocorre com a venda de bolsas, sacolas plásticas, mochilas e pochetes, sendo lojas e estandes do beco especializados nestes mesmos itens, assim como as empresas adjacentes.

\footnotetext{
${ }^{4}$ A efetivação da prancha foi proporcionada a partir da obtenção de mais de 450 tomadas com câmera digital traseira Dual Autofocus Pixel (lentes de 12 e 8 megapixels) do aparelho celular, posteriormente agrupadas em seções contíguas, visando oferecer maior coerência e uma fotocomposição eficaz. Durante a manhã de trabalho de campo (das $9 \mathrm{~h}$ ao meio-dia), foram capturados vários momentos ao longo de uma das paredes do beco, à guisa de gerar uma "área de cobertura", com a câmera em altura aproximada de um metro do piso, apontada em ângulo reto para a frente oposta do logradouro, de modo a preservar ao máximo a identidade das pessoas, visto que se tratava de um dia comum de expediente, com a presença de muitos consumidores e trabalhadores do comércio popular.

${ }_{5}^{5}$ Fortunato Russo Sobrinho, sito à travessa Beco do Marroquim, $\mathrm{n}^{\mathrm{o}}$ 178, comércio varejista de artigos do vestuário e acessórios, de uma família de origem italiana, presente há mais de 120 anos no mercado.
} 

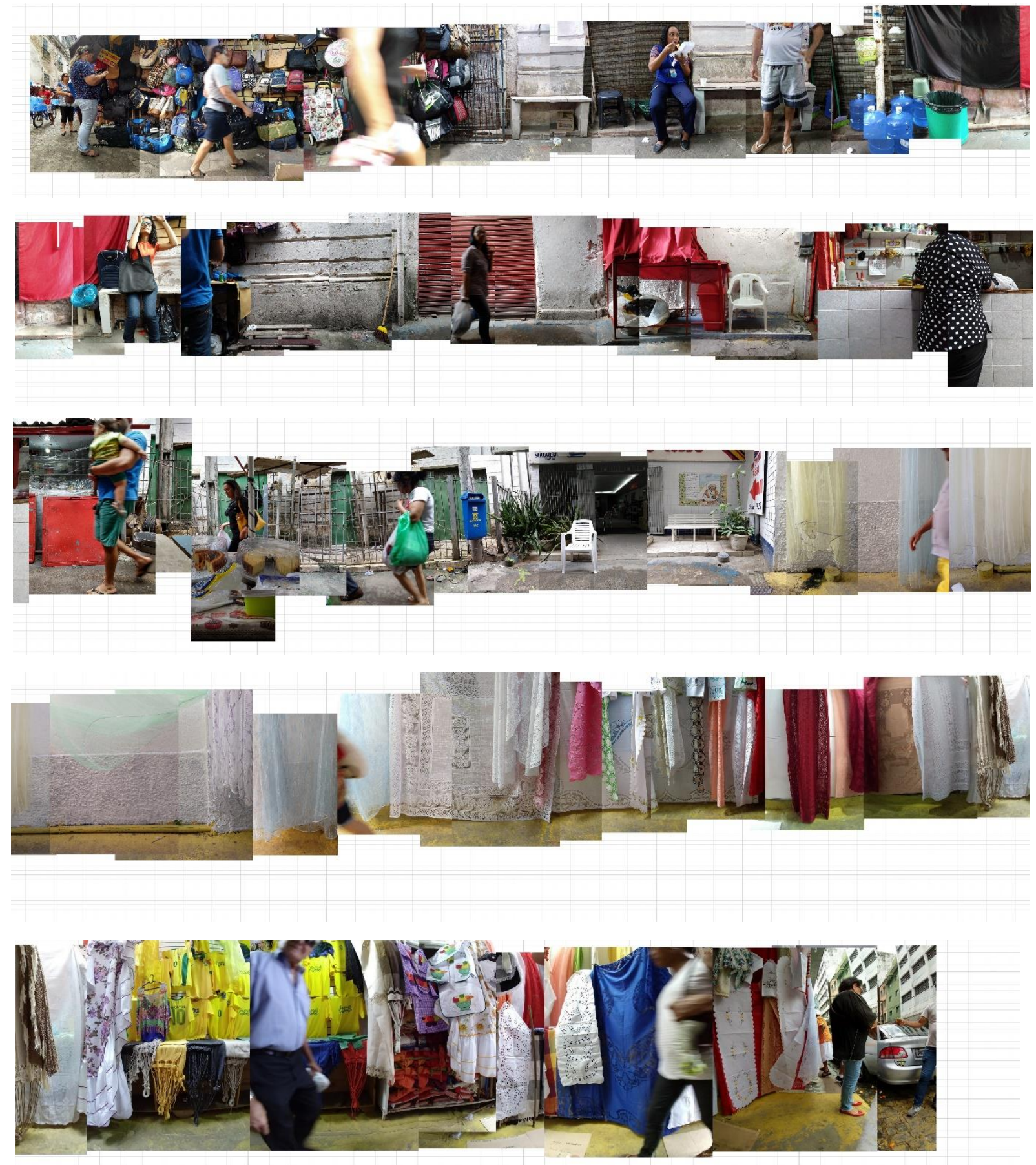

Figura 1- Fotomontagem do Beco do Marroquim.

Fonte: Os Autores, $2018^{6}$.

\footnotetext{
${ }^{6}$ A fotomontagem de um panorama fantasmático do beco vai transformando um espaço com visão obstruída em uma paisagem admirável em seu conjunto. Na montagem não houve deslocamento proposital de barreiras, tampouco procedemos a qualquer tipo de direção de arte.
} 
Interregno da travessa é mais heterogêneo, comportando espaços para o consumo de alimentos e bebidas (desde fiteiros e lanchonetes até restaurantes self service), quiosques para reparos de bolsas e roupas, bancas de jogo do bicho, loterias, fundos de lojas ou de armazéns sem uso comercial da face interna da passagem e mesmo uma minipraça em homenagem a uma personagem emblemática do local, a pedinte Maria. Não deixa de ser surpreendente que a via, hoje bem zelada pelos comerciantes (que inclusive a fecham à noite, com grades, mediante autorização da prefeitura ${ }^{7}$ ), possua trecho em honra à uma mulher negra, pobre e esmoler, pois remete-se aos tempos em que as vielas carregavam a tônica de espaços relegados aos pobres do Centro da cidade.

O Beco do Marroquim já foi associado à existência de vários cabarés e prostíbulos neste trecho em estudo ${ }^{8}$. Por mais que se possa arguir que o espaço sirva de isolamento para que a entrada da loja de tecidos permaneça livre e desimpedida (inclusive de novos pedintes), não há como negar a força dessa figura popular a ponto de ser decantada em mural colorido, pracinha e poesia no local mesmo em que passou a vida mendigando.

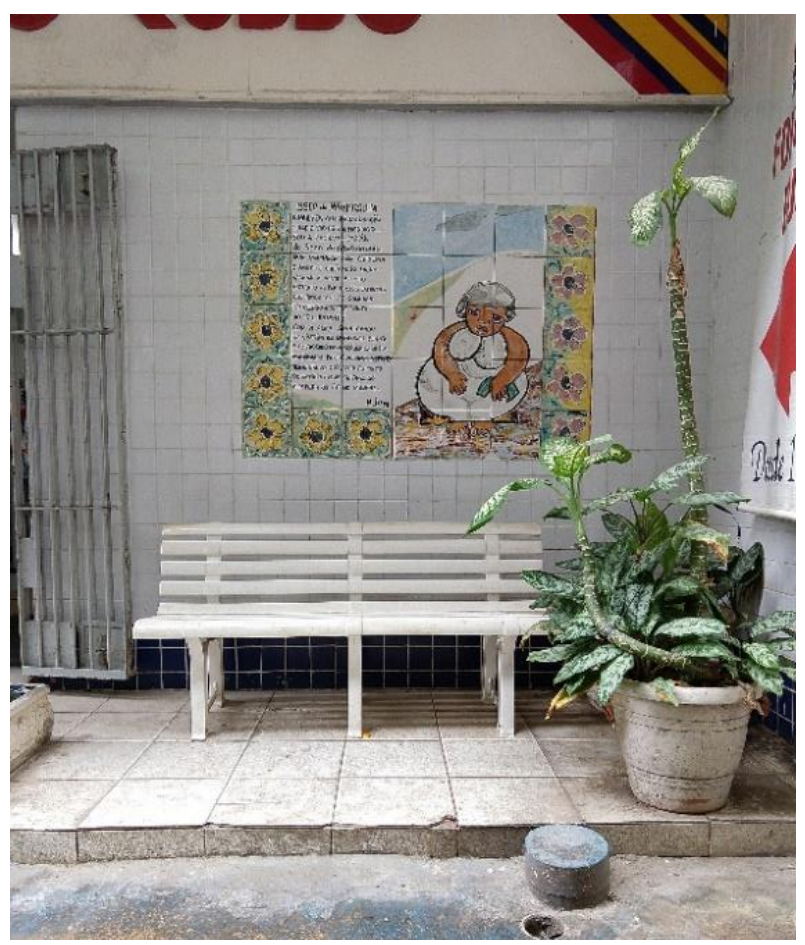

Figura 2 - "Pracinha” no interior do Beco do Marroquim, espaço de pausa no fluxo em homenagem à pedinte Maria.

Fonte: Os Autores, 10 de julho de $2018^{9}$.

\footnotetext{
7 Informação verbal dos comerciantes, durante o trabalho de campo em que constatamos a existência do gradeamento e indagamos sobre sua legalidade, uma vez que as vias são espaços públicos.

${ }^{8}$ Informação verbal de proprietários de lojas no local, durante trabalho de campo.

${ }^{9}$ No painel de azulejo intitulado "Beco do Marroquim", assinado por MJO (1998), a mendiga negra, de olhar resignado, é descrita como à espera de um íntimo milagre: "a alma suplicando um vintém de qualquer olhar ou o trocado de qualquer carinho". 
$\mathrm{O}$ ato de fazer as fotos para o mosaico nos obrigou a uma expectativa: detivemos um pouco o movimento e atentamos de maneira mais acurada para cada seção da via em suas especificidades. Uma passagem de fluxos rápidos revelou-se em mais detalhes a partir dessa "espera", como diria Maurício Lissovsky (2010).

Desse modo, a experiência mosaico-panorâmica do beco nos interpelou para uma "educação do olhar", uma vez que nos revelou algumas surpresas, dentre elas a constatação de um número significativo de mulheres usuárias daquele espaço, fato que havia passado ao largo pela nossa devoção inicial aos aspectos puramente morfológicos do lugar. Além dos achados racionais e objetivos, decerto relevantes, o processo em si de interpretar a cena resultante de nossa composição nos exigiu mais atenção, de forma a garantir coerência e legibilidade à metodologia proposta.

O envolvimento poli sensorial com a paisagem exígua do Marroquim em termos de engajamento corporal completo (calor, trânsito intenso de pessoas, ruídos e odores fortes, variabilidade da luz vertical, etc.) desafiam a redução do universo complexo das vielas em uma justaposição seriada de imagens. Preferimos pensar, ao invés de redução, em sugestão de elementos significativos para a composição de um quadro geográfico enquanto instrumento de descoberta. E quais foram as principais revelações deste recurso heurístico à fotografia mosaica? Discutamos alguns insights e impasses.

\title{
Revelações geográficas da fotografia: cliques inconclusos
}

\begin{abstract}
A fotografia cria uma visão do mundo a partir do mundo, molda um imaginário novo, uma memória não seletiva porque cumulativa. Em sua superfície o tempo e o espaço inscrevem-se como protagonistas absolutos, não importa se imobilizados, ou até melhor se imobilizados porque passíveis de uma recuperação, feita de concretude e devaneio, na qual a aparente analogia se revela seleção, construção, filtro (FABRIS, 2008, p.36, grifo nosso).
\end{abstract}

As principais recuperações advindas desse jogo entre concretude e imaginação podem ser resumidas como se segue.

\section{a) Imagens panorâmicas são metáforas visuais de paisagens}

É interessante iniciar reafirmando como a larga experiência das Ciências Sociais sobre fotografia nos foi essencial, desde a Antropologia (CAIUBY NOVAES, 2015), 
passando pela Sociologia (MARTINS, 2011) até a História da Arte (FABRIS, 2008), dentre outros campos disciplinares. Durante a produção concomitante da fotografia e do artigo nos demos conta de que mesmo em relação a investigações sobre paisagens panorâmicas convencionais a existência de um raciocínio composicional se faz presente.

A este título pode-se compreender a propriedade de realizar arranjos mentais sobre o espaço percebido a partir de trabalhos como o dos antropólogos Rafael Devos, Viviane Vedana e Gabriel Barbosa (2016) referente à técnica de vigiar peixes em ambiente litorâneo. Esses autores produziram, junto aos pescadores e em seus pontos de tocaia, panoramas fotográficos que apresentassem os lugares de vigia do mar com base nas práticas dos sujeitos sociais, criando imagens "irreais" (tais que nossa fachadaprancha) dos seus sistemas de cognição em ação. Para esses autores, panorama refere-se a "esquemas de cognição que tentam apresentar em imagens sistemas complexos de interação entre diferentes fontes de informação" (DEVOS et al., 2016, p.50).

Os panoramas provocaram estranhamento nos pescadores, que não conseguiram reconhecer naquelas imagens suas práticas cotidianas. ${ }^{10}$ Quer dizer, mesmo uma paisagem panorâmica de um largo espaço aberto, como a beira-mar, não se mostra ao olhar per se, tal que dado perceptível da natureza, imediato, mas como um esforço cognitivo de demonstração, decorrente de nossa inserção e movimento no mundo:

[...] podemos retomar aqui Gibson (1986), que demonstra o quanto a percepção visual não se reduz nem à vista panorâmica, nem à vista em perspectiva. Gibson argumenta que embora a visão humana, com dois olhos frontais, esteja sujeita ao efeito de perspectiva ao compor uma imagem, a percepção do ambiente não se dá com apenas uma vista, ou com a sucessão de vistas, como poderíamos supor, mas pela varredura ótica que desempenhamos no ambiente enquanto nos deslocamos. Tais ações perceptivas, que são feitas em um sistema móvel no ambiente (por olhos, em uma cabeça ou sobre ombros e pernas), permitem-nos avaliar relacionalmente o que vemos, podendo então elaborar noções do que está atrás, ao lado, abaixo, perto e longe a partir de cada ponto que nos situamos (DEVOS, VEDANA, BARBOSA, 2016, p.49, grifos nossos).

A varredura ótica exige a ação de um sujeito ativo tanto por ocasião de esquadrinhar o espaço em movimento quanto no momento de recompô-lo em uma imagem coerente e comunicável. Acrescentaríamos a isto o debate sobre regimes escópicos, partindo do princípio de que "a visão, tal como a linguagem é altamente

10 Para ver imagens do Pescador e panorama do local conhecido como Vigia do Passo, Ilha de Florianópolis, Santa Catarina. Autor: Rafael Devos (2013) in DEVOS, VEDANA e BARBOSA (2016, p.56), disponível em: http://www.revistas.usp.br/gis/article/view/116350, acesso em 23/07/2020. 
estruturada e contextual” (CAIUBY NOVAES, 2015, p.13), uma vez que as ações perceptivas não se dão numa tábula rasa virgem de orientações e modos de olhar. Interessa-nos, no momento, compartilhar a ideia de que a realização de panoramas (mesmo convencionais) é de fato uma agência: atentar ao mundo e realizar ativamente uma mirada de conjunto para se saber "onde nos situamos".

$\mathrm{O}$ adestramento geográfico do olhar tende a nos fazer ver um panorama "tal como ele é", um dado da natureza: amplitude do litoral emoldurado por montanhas, magnitude do céu, imenso mar sem fim e uma pessoa captando automaticamente tudo isso. Só que não é bem assim que acontece para o sujeito ali plantado: pescadores estão tocaiando peixes, não contemplando a priori o mundo em CinemaScope. De fato, ao verem os panoramas produzidos pelos antropólogos, eles ficaram "espantados” com aquela visão, tão diferente da sua!

Apesar dos pressupostos teóricos diferentes, compartilhamos com tais reflexões a ideia de que panoramas seriam esquemas de cognição que tentam apresentar em imagens sistemas complexos de interação entre diferentes fontes de informação ${ }^{11}$. A primeira revelação parece assombrosa e óbvia ao mesmo tempo: qualquer panorama é uma montagem. Seja de uma paisagem panorâmica ou não. Nosso mosaico do claustrofóbico Beco do Marroquim se compõe de modo análogo aos grandes panoramas de espaços abertos. O panorama-mosaico é uma metáfora visual, como qualquer outro panorama que pretende tornar admirável uma paisagem. Dito de outra maneira, apesar de diferentes, paisagens panorâmicas e não panorâmicas podem ser fruto da mesma razão metafórica.

\section{b) Panoramas são ferramentas para criar quadros geográficos}

Confirmamos, através de nosso procedimento fotográfico-investigativo, algumas injunções trazidas anteriormente ao debate no X Simpósio NEPEC,

\footnotetext{
${ }^{11}$ Os autores do estudo sobre vigias de pesca apoiam-se na noção de "educação da atenção" de Tim Ingold (2010) e buscam, mesmo usando fotografias, trilhar uma abordagem não-representacional do espaço. Para essa corrente, a produção de fotos panorâmicas vai além de simples representações, pois “[...] nos estimula a ação, um gesto tão importante quanto aquele que produz a perspectiva. Enquanto a visão em profundidade provoca movimentos de foco com os olhos em primeiro, segundo e terceiro plano, a fotografia panorâmica provoca o movimento que Gibson chama de 'olhar ao redor', pois apresenta imagens em ângulos além de $160^{\circ}$ horizontais e $75^{\circ}$ verticais, portanto mais amplos do que a capacidade de visão humana (em referência a um observador imóvel). Na panorâmica, a informação está disposta mais lateralmente do que em profundidade. É preciso girar a cabeça, mover o corpo, olhar um canto em relação aos outros, avaliar direções de movimento relacionais” (DEVOS, VEDANA, BARBOSA, 2016, p.49). Sem entrar no debate representações versus sistemas emergentes de educação da atenção, acreditamos que a ideia de interação sujeito-paisagem é crucial para compreendermos o processo de razão metafórica inerente ao ato de compor panoramas.
} 
(VASCONCELOS e MACIEL, 2016) e no XI Simpósio NEPEC (Palestra). Uma das mais importantes refere-se ao imperativo de ser a paisagem um conceito muito mais complexo do que panorama. Este seria apenas um estratagema para dar conta de uma ampla correlação de fatores e localizações espaciais a que chamamos paisagem. Portanto, panorama seria um modo de compor quadros geográficos para interpretar a ordem espacial das coisas. Compomos panoramas como uma ideia de paisagem, para que possamos melhor apreciá-la, investigá-la e dominá-la. O recurso aos mosaicos de imagens permite que paisagens recônditas, com vistas atravancadas, possam ser integradas em um tipo de mirada similar ao panorama.

A paisagem de espaços recônditos e obstruídos, como os becos, caberia numa abordagem não-redutora de panorama, isto é, aquela que considera todo artefato panorâmico um mosaico, não importando a amplitude do horizonte. Quer dizer, panoramas fotográficos como os que geramos são "quadros geográficos", descrições sistemáticas com base locacional, visando criar condições de visualização, análise e interpretação da espacialidade de fenômenos. Desde que associados a procedimentos de localização e situação (e não apenas deleite estético), constituem ferramentas científicas, como o conceito de paisagem.

Em seguida, ao fazermos como complemento à fachada-prancha uma série de fotografias em profundidade (perspectiva) através do ato de caminhar pela viela, nos ocorreu que um procedimento possível para dar conta da espacialidade de ruas e espaços estreitos seja a fabricação, pelas pessoas, de vários quadros que se integram mentalmente, resultando em uma ideia-colagem sobre as especificidades de sua geografia - como se houvesse um procedimento de aderência vertendo a um panorama composicional por efeito do movimento. Mais ou menos como o trabalho de artistas que se devotam à diversos tipos de colagens, dentre os quais o mais conhecido é David Hockney, pintor e fotógrafo inglês ligado à pop art. No Brasil, a fotógrafa Cláudia Jaguaribe expande formatos tradicionais da fotografia gerando construções digitais panorâmicas e "fotoesculturas" que também são fontes de inspiração para o diálogo entre arte e ciência. A analogia do panorama com estes tipos de artefatos evidencia a deambulação do olhar, antes, durante e depois do tempo da fotografia de paisagem.

Em uma de suas criações de grande popularidade, a foto-colagem de mais de setecentas peças "Pearblossom Highway" $(1986)^{12}$, Hockney mostra um cruzamento em

\footnotetext{
12 "Pearblossom Hwy." Autor: David Hockney (1986). Uma das mais icônicas obras desse reconhecido artista inglês, referência em relação às montagens na pintura e na fotografia. Um dos exemplos mais ESPAÇO E CULTURA, UERJ, RJ, JUL./DEZ DE 2020, N. 48, P. 137-157 http://www.e-publicacoes.uerj.br/index.php/espacoecultura/
} 
uma ampla paisagem de estrada, que alude através de vários elementos icônicos ao oeste dos Estados Unidos. A obra exibe uma dupla visão, cortada ao meio pela rodovia, como descreveu o próprio artista: do lado do motorista há placas e sinais de trânsito que indicam o modo de ver dos que guiam um veículo; já no lado do passageiro, o olhar é mais solto e divaga descompromissado com a sinalização (o artista é britânico, portanto, o condutor imaginário estaria à direita).

Dentre muitas possíveis leituras, observa-se que o lixo acumulado no acostamento sugere viajantes desleixados, enquanto as bordas imprecisas da estrada apontariam para a interrupção da paisagem do deserto, rasgada pela via ${ }^{13}$. Hockney costuma descrever o seu trabalho mais como um desenho do que uma peça fotográfica, uma vez que apresenta composição em múltiplas camadas representando diferentes pontos de vista, por oposição a uma fotografia em tomada única. Como quer que seja, ao manusear as fotos em composição, ele cria um tipo daquilo que estamos aqui chamando de quadro geográfico (GOMES, 2017) sobre estradas e o imaginário do deserto americano. Há mais informações ali, incluindo a história de vida do autor e as idiossincrasias da paisagem no interior da Califórnia.

Já Claudia Jaguaribe percorre uma linha evolutiva da fotografia panorâmica de paisagem no Rio de Janeiro, expandindo seus olhares para São Paulo. Duas de suas exposições são importantes para o nosso debate: Entre Morros (2012) e Entre Vistas (2014); a primeira faz uma releitura do cenário urbano e natural do Rio de Janeiro, transitando entre o factual e o artístico para criar imagens de um realismo desconcertante. Segundo Sergio Burgi (2012), as imagens de Jaguaribe estruturam-se a partir de elementos da contemporaneidade, como simultaneidade das informações visuais, suporte digital, busca do plano inusitado, ambiguidade entre perspectivas clássicas e informação documental. Assim, incorpora questões atuais para a fotografia em que "o olhar transcende o documental e incorpora a reflexão sobre o tempo presente em imagens construídas que provocam estranhamento e imersão crítica no universo registrado” (BURGI, in JAGUARIBE, 2012, s./p.).

O segundo trabalho da mesma fotógrafa, reúne imagens panorâmicas de espaços interiores da cidade de São Paulo, mostrando momentos de seus habitantes (panorama

flagrantes de evidência de um processo construtivo dos panoramas, partindo das qualidades de um espaço geográfico para chegar à paisagem enquanto um discurso visual altamente organizado. Disponível em: http://www.getty.edu/art/collection/objects/105374/david-hockney-pearblossom-hwy-1 1-18th-april1986-2-british-april-11-18-1986/, acessado em: 08/09/2020.

13 Os comentários acerca da fotomontagem possuem considerações extraídas de: http://www.davidhockney.org/pearblossom-highway/, acessado em 11 de novembro de 2020. Tradução nossa. 
interno) e a vista de suas janelas para a cidade (panorama externo), sempre no cair do dia, em locais com grandes contrastes e diferenças, incluindo luxuosos apartamentos e favelas ${ }^{14}$. As fotos são sanfonadas (dobras múltiplas) de modo que o próprio manuseio possa criar novos ângulos, resguardando ainda a possibilidade de que a visualização seja integral pela abertura total dos vincos (ver figura 9). Em entrevista ao Estúdio Madalena Produtores Culturais, Cláudia Jaguaribe assim explicou sua obra:

O espaço da cidade é o espaço da vida, ambiente concreto, que afeta as pessoas. É onde elas se expressam tanto na intimidade quanto na forma de utilizar o espaço público. Neste projeto, tento fazer a ligação entre o espaço privado, o seu morador - a partir da imagem da sua casa - e o espaço público, a cidade. O resultado é um panorama duplo da visão de dentro para fora e da privacidade dos habitantes ${ }^{15}$.

Nos dois exemplos acima evocados ambos os artistas mobilizam diferentes técnicas de produção de panoramas a partir de fotos que operam à guisa de quadros interpretativos sobre a ordem espacial de vários fenômenos que os interessam. Tal como a arte, a geografia pode compor panoramas para apreender aspectos que integram paisagens, sejam recônditas, abertas, públicas ou privadas, de modo a torná-las inteligíveis. O procedimento para revelar o beco carrega grande similaridade com essas metodologias advindas da arte. A linguagem das paisagens mosaicas (panorâmicas e nãopanorâmicas) busca congregar sentidos através de um sistema de posições e localizações que se transmite visualmente da maneira mais eficaz possível: quase como um lance do olhar.

\section{c) "Panoramizamos" espaços não aptos a grandes vistas de modo a torná-los admiráveis e adivinhar seu porvir}

Decerto o não-panorâmico pode dar conta de espaços restritos ao emergir como labirinto retilíneo ou quadricular de imagens que a ação cultural dos sujeitos põe em composição, a partir de vivências do transitar, ver e estar. Vimos os becos inicialmente como aberturas curiosas, aspectos quase folclóricos do "vuco-vuco" que é o Bairro de São José, por onde passamos a transitar de modo mais atentivo; em seguida, pesquisas correlatas sobre a dinâmica de aluguel nesta parte da cidade trouxeram a informação

\footnotetext{
${ }_{14}$ Vide http://claudiajaguaribe.com.br/entre-vistas-livro/, acessado em 10/10/2020.

${ }^{15}$ Entrevista disponível em: http://estudiomadalena.com.br/entrevistas-claudia-jaguaribe/, acessado em $10 / 10 / 2020$. 
inesperada de seu alto valor imobiliário, mesmo que pouco expostos, o que nos fez indagar sobre o aparente paradoxo de sua invisibilidade através de uma imersão pela imagem, do estar ali para reavaliar o como vemos, em procedimento permanente de reavaliação. Uma educação do olhar, em qualquer sorte.

Como o movimento tornou-se imperioso e a fixação de imagens uma obsessão na contemporaneidade, precisamos lidar com esta outra contradição. Percebemos que nossa maneira de ver e representar o mundo está sendo cada vez mais tributária de uma incessante colagem de pequenos pedaços, fragmentos de cotidiano, o que nos possibilitou trazer a experiência de composição do falso panorama como uma forma de metáfora das paisagens recônditas. O quadro geográfico em foto-mosaico é uma forma de pensar atual e que vamos nos oferecendo durante a construção daquele "dossiê interminável” de que fala Susan Sontag (2004, p.173) sobre a exploração e duplicação fotográfica do mundo. Neste sentido, procuramos produzir imagens geolocalizadas e conectadas para oferecer uma possibilidade de contemplação a espaços onde o afastamento é (quase) uma impossibilidade. A gênese do mosaico-panorama reafirmou a utilidade mágica da fotografia para uma análise geográfica.

No duplo artístico do beco em paisagem, houve a possibilidade de descobrirmos novas maneiras de articular seus elementos morfológicos, expressivos e imaginários. $\mathrm{O}$ banal torna-se digno de vislumbre e, por conseguinte, crescem suas chances de valorização positiva - mais uma mágica advinda da fotografia. A materialidade do beco, como temos lembrado desde publicações anteriores sobre o tema, encontra-se protegida, pois integra a paisagem secular das igrejas, pátios e sobrados seculares do Centro Histórico do Recife, no interior de um perímetro tombado. Se bem que em mudança veloz, de "maus lugares" às áreas de considerável valorização comercial, algumas características das vielas sobrevivem: atalhos para os apressados, serviços especializados para consumidores habituais e insiders, encontros para outros tantos. Abrigos para o sol escaldante ou para a chuva que atrapalha o caminhar e as compras por outras ruas.

Se as normativas urbanísticas da Cidade do Recife pouco contemplam as especificidades dos becos, surgem ações como o referido Guia Comum do Recife, a partir da sociedade civil, atestando a existência de um movimento difuso pela sua cidadania paisagística. A materialidade desses espaços, agenciada e apropriada de forma peculiar por vários sujeitos sociais, encontra imagens politicamente eficazes que recompensam mais que sua utilidade, seu caráter de bem comum de uso público. Assim, o nosso fotomosaico desdobra - de modo ínfimo, mas seguro - essas novas possibilidades de ser 
paisagem que as vielas passam a corporificar. Retomando Lissovsky (2010), a fachadaprancha nos dá um espaço escapado do torvelinho de tempos, guardando um questionamento crucial acerca de sua sobrevida: o que, neste recorte fotografado, não obstante a história que ali fluiu, ainda será?

\section{Questões finais - A imagem revela mais que o fotografado}

Já se disse que o geógrafo é um "olho" e a geografia uma maneira de ver. Jamais se pretendeu fazer do geógrafo uma Kodak insensível (Pierre Monbeig, 1957, p.236)

Nos exemplos científicos e artísticos aqui trabalhados, bem como tomando o nosso próprio trabalho como método de reflexão, fica claro que muitos problemas inerentes às representações do espaço pela geografia se replicam: a escolha do que e como mostrar, a importância da escala e o diálogo entre elementos diferentemente dispostos no espaço. Todas as partes do desenho de pesquisa continuam a depender, sobretudo, da sensibilidade dos geógrafos por trás das "Kodaks" pós-modernas. Em que pese a multiplicação exponencial dos aparatos técnicos na era da informação, persistem dilemas atinentes ao debate sobre paisagem em geral, e sobre a maneira como devemos ou podemos lançar mão de panoramas construídos para refletir sobre elas.

Como atesta Teresa Alves, os centros das cidades têm sucumbido às pressões de todo tipo, como acontece também no bairro histórico de São José na dinâmica imobiliária recente (VASCONCELOS, LACERDA E MACIEL, 2018). Daí são necessárias medidas políticas que possibilitem a "valorização de paisagens culturais únicas", como acreditamos constituir os becos do Recife. Para Alves, face a tal circunstância de fragilidade de nossas heranças urbanas "a noção de paisagem tem de ser necessariamente modificada, reassumindo outros valores sociais e culturais; caso contrário, estamos condenados a viver num mundo sem paisagem” (ALVES, 2001, p.71).

A proposição da metodologia da fachada-prancha do beco aqui estudado seguiu essa pista: não que os becos não possuam paisagem por serem estreitos e com visão obstruída; nossa noção de paisagem é que precisa ser reconsiderada para que as modestas vias de ligação possam integrar de maneira mais proativa à paisagem cultural do Centro Histórico, afinal são espaços que vivenciam grande fluxo de pessoas e têm sido alvo de crescente demanda por reconhecimento (inclusive paisagístico). Neste sentido, ao propor uma metáfora visual de paisagens não-panorâmicas adentramos em debates que se 
prolongam para além da fotografia e mesmo da geografia, incluindo arte, informação, ética e política: cidadania paisagística. Por outro lado, divisamos um pouco do poder das técnicas artísticas de colagem, fotomontagem etc., para dar conta da multiplicação de miradas sobre o espaço, que é própria de nosso tempo e não apresenta sinais de esgotamento.

Reforçamos algumas conclusões de relevância para a condução de áreas urbanas protegidas, como perceber o conteúdo espacial e arquitetônico dos becos enquanto partes de um ato cultural (LACERDA e LEITÃO, 2016), constituindo bens patrimoniais dignos de conservação, não se admitindo que venham a desaparecer. Nos juntamos ainda a Barbosa (2018, p.55) quando, apoiado em Sgard (2010), atesta que a paisagem corresponde a um objeto e fenômeno político com horizonte ético, envolvendo pensar o presente e o futuro dos espaços de vida da cidade como palcos da existência de múltiplos sujeitos sociais.

Ainda assim, a utilização de fotografias para trazer à vista uma ideia de conjunto do Beco do Marroquim trouxe-nos mais perguntas que respostas. Indagamos, de início, se não seria a "cognição em mosaico" das fotografias não-panorâmicas algo compartilhado sobretudo com o cinema - filmes são fotos em sequência - ou mesmo com a produção cartográfica - mapas são colagens de diferentes áreas em uma escala que torna o todo disponível ao olhar. Tratar-se-iam tão somente de diferentes tipos de dispositivos resultantes do raciocínio espacial? Ou, ao contrário, novas técnicas e recursos artísticos exigiriam outras razões geográficas na era dos sujeitos geolocalizados?

Paulo César da Costa Gomes sugere que “um 'quadro', seja ele qual for, pela forçosa delimitação que impõe e pela aceitação de que há um sentido entre aquilo que ele reúne, é sempre o ‘desenho’ de um sistema de informações geográficas” (GOMES, 2017, p.94). Como a fotografia hoje está mergulhada cada vez mais nos fluxos informacionais e geotecnologias, caberia uma reflexão, a partir da hipótese de Francis Jauréguiberry e Jocelyn Lachance (2017), de que a conexão às redes de telecomunicação seria tão generalizada que transformaria nossa própria relação com o mundo. Então, que quadros geográficos são esses que se desenham na hipermodernidade? E qual a especificidade da leitura de fenômenos geográficos pela fotografia autoral de paisagens, com os recursos tecnológicos e de geolocalização de que hoje dispomos? 


\section{REFERÊNCIAS BIBLIOGRÁFICAS}

ABRANTES, V. L. C. (2000). Fragmentos de memória das pesquisas geográficas de campo no IBGE (1939-1968): imagens e representações numa abordagem da história oral. (Dissertação de Mestrado), UNI-RIO, Rio de Janeiro.

ALVES, T. Paisagem - em busca do lugar perdido. Finisterra XXXVI, 72, 200 1, p.67 - 74.

ANGOTTI-SALGUEIRO, H. A construção de representações nacionais: os desenhos de Percy Lau na Revista Brasileira de Geografia e outras "visões iconográficas" do Brasil moderno. Anais do Museu Paulista, vol. 13, n. 2, Universidade de São Paulo, São Paulo, Brasil, jul.-dez./2005, p. 21-72.

BARBOSA, D. T. Cidadania Paisagística. Revista de Geografia (Recife), v.35, n.1 (especial), 2018, p.40-59.

BURGI, S. O construído e o documental. In: JAGUARIBE, C. Entre Morros. São Paulo, Editora Cosacnaify, 2012, s./p.

CAIUBY NOVAES, S. (Org.). Entre Arte e Ciência: A Fotografia na Antropologia. São Paulo, Edusp, 2015.

CLAVAL, P. Terras dos homens. A geografia. São Paulo, Contexto, 2010.

DEVOS, R. V.; VEDANA, V.; BARBOSA, G. C. Paisagens como panorama e ritmos audiovisuais: percepção ambiental na pesca da Tainha. GIS - Gesto, Imagem e Som - Revista de Antropologia, v. 1, p. $41-58,2016$.

FABRIS, A. A invenção da fotografia: repercussões sociais. In: FABRIS, A. (Org.) Fotografia. Usos e funções no século XIX. São Paulo, EdUSP, 2008, p.11-37.

MORAIS, B. R. F.; CESAR, V. et al. (Orgs.). Guia Comum do Centro do Recife. Uma arqueologia do presente. 1a. ed. Recife: Livrinho de Papel Finíssimo, 2015.

GIBSON, J. The ecological approach to visual perception. New York: Psychology Press, 1986.

GOMES, P. C. C.; RIBEIRO, L. P. A produção de imagens para a pesquisa em geografia. Espaço e Cultura, UERJ, RJ, n. 33, p.27-42, Jan./Jun. 2013

GOMES, P. C. C. Quadros Geográficos. Uma forma de ver, uma forma de pensar. Rio de Janeiro, Bertrand Brasil, 2017.

INGOLD, T. Da transmissão de representações à educação de atenção. Educação, Porto Alegre, v. 3 n.1, 2010, p.6-25.

JAGUARIBE, C. Entre Morros. São Paulo, Editora Cosacnaify, 2012.

Entre Vistas. São Paulo, Editora Estúdio Madalena, 2014.

JORNAL DO COMMERCIO. Vias estreitas e abertas da cidade. Caderno Arrecifes, ano 02, $n^{\circ} 67$, Recife, 22 de julho de 2012. Disponível em: https://www3.ufpe.br/agencia/clipping/index.php?option=com_content\&view=article\&id=1 1186:vias-estreitas-e-abertas-da-cidade $\&$ catid $=129 \&$ Itemid $=122$, acessado em 07 de novembro de 2020 . 
JAUREGUIBERRY, F.; LACHANCE J. Le voyageur hypermoderne. Partir dans un monde connecté. Toulouse, Éditions Érès, 2017.

KOSSOY, B. Os tempos da fotografia: o efềmero e o perpétuo. Cotia, São Paulo: Ateliê Editorial, 2007. LACERDA, N.; LEITÃO, L. O espaço na geografia e o espaço da arquitetura: reflexões epistemológicas Cadernos Metrópole, São Paulo, v.18, n. 37, p.803-822, set/dez 2016.

LEITE, F. M. \& ABRANTES, V. L. C. (Orgs.). As expedições geográficas do IBGE. Um retrato do Brasil, 1941-1968. Rio de Janeiro, IBGE Gerência de Bibliotecas e Acervos Especiais, 2018.

LISSOVSKY, M. Dez proposições sobre a fotografia do futuro. Fórum Latino-americano de Fotografia, São Paulo, 24 de outubro de 2010. Disponível em: http://www.dobrasvisuais.com.br/wp-content/uploads/2010/10/Dez-

proposi\%C3\%A7\%C3\%B5es-sobre-a-fotografia-do-futuro.pdf, acessado em: 1 de novembro de 2020.

MARTINS, J. S. Sociologia da fotografia e da imagem. São Paulo, Contexto, 2011.

MONBEIG, P. Novos estudos de geografia humana brasileira, São Paulo, Difusão Européia do Livro, 1957.

NASCIMENTO, R. A. STEINKE, V. A. Apontamentos teóricos para uma relação entre paisagem e iconografia na geografia. Revista Ra'eGa Espaço Geográfico em Análise, Curitiba, v. 44, p. 21-35, maio/2018.

RIBEIRO, R. W. Paisagem, Patrimônio e Democracia: Novos desafios para políticas públicas. In: CASTRO, I. E. de; RODRIGUES, J. N; RIBEIRO, R. W. (Orgs.). Espaços da Democracia: Para a agenda da Geografia Política contemporânea. Rio de Janeiro: Bertrand Brasil, 2013, p.235-259.

ROGER, A. Court traité du paysage. Paris, Ed. Gallimard, 1997.

SAlaZAR, M. Mundo Mosaico. A estetização do cotidiano no Instagram. Curitiba, Kotter Editorial, 2018.

SEEMAN, J. Cartografia e cultura: abordagens para a geografia cultural. In: Rosendahl, Z.; Lobato Corrêa, R. (Orgs.). Temas e caminhos da geografia cultural. Rio de Janeiro: EdUERJ, 2010, p. $115-156$.

SGARD, A. Une «éthique du paysage» est-elle souhaitable? VertigO. Vol. 10, n. 01, Avril/2010. Disponível em: http://vertigo.revues.org/9472, acessado em 10 de novembro de 2018.

SONTAG, S. Sobre fotografia. São Paulo, Companhia das Letras, 2004.

VASCONCELOS, P. B.; MACIEL, C. A. A. No mais entranhado da cidade: imagens e espacialidades dos becos no Centro Histórico do Recife. Espaço e Cultura (UERJ), vol. 1, p.116$138,2016$.

VASCONCELOS, P. B.; MACIEL, C. A. A.; LACERDA, N. "Pelas frestas e becos do patrimônio": o lugar do (in)visível no Centro Histórico protegido do Recife. Revista de Geografia (Recife), v. 35, p. 89-102, 2018.

VELAZCO e CRUZ, N. Apresentação. In: SALAZAR, M. Mundo Mosaico. A estetização do cotidiano no Instagram. Curitiba, Kotter Editorial, 2018, p.13-17. 